\title{
Synchronic digital stereophotography and photogrammetric analyses in monitoring the flow of liquids in open channels
}

\author{
Artur Janowski ${ }^{a}$ Jakub Szulwic ${ }^{b}$ \\ ${ }^{a}$ Institut of Geodesy, Faculty of Geodesy and Land Management of the University of Warmia and Mazury in Olsztyn, 10-957 Olsztyn, Poland \\ ${ }^{b}$ Department of Geodesy, Faculty Of Civil and Environmental Engineering, Gdansk University of Technology, 80-233 Gdańsk, Poland
}

\begin{abstract}
The authors present the results of their research into photogrammetric documents based on synchronic digital images. Examples presented in the paper indicate the value of synchronic stereophotography in registering phenomena connected with liquids. Combining synchronic stereophotography with photogrammetric methods has allowed the authors to develop an application useful for monitoring the flow of a liquid in an open channel. The paper is supplemented by the scientific approach to the development of a stereo pair using a proprietary algorithm and data elaboration. The tasks performed allow an assessment of the accuracy of the results obtained and indicate significant usefulness of photogrammetry and synchronic photography methods in liquids measurements and monitoring.
\end{abstract}

Keywords: flow in open channels; close-range photogrammetry; SVD; essential matrix; eight-point algorithm.

\section{Introduction}

The problem concerning the measurement of the liquid velocity in open channels is an important issue for the calculation of flows volumes. The open channel can be understood as both open riverbeds and channels and each duct with the free surface of the liquid. In the context of the application of the described method, the open channel concept can be extended to the waters released as a result of the failure of hydraulic engineering devices and flood waters occurrence.

Liquids in the open pipes are limited with channel walls, whereas they surface-border on the air and form a free surface of liquid. The liquid flow is not subject to pressure and it is related to the fluid properties and the levelling decrease of the bottom, roughness of channel walls and the gravity. The velocity distribution in the horizontal and vertical section is not uniform and the equations used to determine the average velocity and the velocity distribution are empirical or semiempirical formulas. Therefore, the choice of measurement and computational method is significant for the achieved results $[1]$.

Methods of the measurement of the flow velocity, used in open channels:

- velocity-surface method (using a hydrometric grinder or float);

- declivity-surface method;

- index dilution method;

- hydraulic methods (swelling and reducing);

- ultrasonic methods;

- optical methods (using laser Doppler anemometry or PIV, i.e. Particle Image Velocimetry);

- electromagnetic methods [2].

Due to the difficulties with the flow modeling in open channels and the large impact of the weather conditions (wind, ice) [1], the float method gives the largest measurement unreliability. In the hydrology, the surface measurement is considered as indicative. At the same time, this method is cheap and easy to implement. It consists in measuring the surface speeds with the usage of floats on the chosen section of the open channel. Conditions relating to the procedures have been standardized (ISO). Basically, this method is applicable in case of unavailability or difficult installation of hydrometric equipment, as well as the confluence of ice floes, flows of the great waters at very low water velocities and for the purpose of the longterm observation of the water mass movement, e.g. in lakes. Measurements with the use of floats have been known for

Corresponding author: Jakub Szulwic. E-mail address: jakub.szulwic@pg.gda.pl

http://dx.doi.org/10.3846/enviro.2014.079

(C) 2014 The Authors. Published by VGTU Press. This is an open-access article distributed under the terms of the Creative Commons Attribution License, which permits unrestricted use, distribution, and reproduction in any medium, provided the original author and source are credited. 
a long time [3] and they are still used today for measuring water and other liquids flow rates [4]. In the literature there are also non-standard situations associated with the analysis of other liquids flow and related to the usage of float method [5].

For open channels and flood waters, numerous analyzes and hydrological models were made. They are important for the evaluation of flow velocity measurement method including the surface measurements (using floats) [6], [7]. Also the manner proposed in the article has to be included in this method. Having in mind the imperfections of the method of measuring flow velocity using floats, many authors mention registrations using photographic images and their relationship with PIV (the use of a laser light scattering on particles that follow the flow). To extend it is possible to use photography and video recording methods for the analysis of water surface and eddy currents in LSPIV technology where the plane generated by laser is replaced with boundary of water and air center or transparent walls of laboratory channels [8], [9].

An interesting issue is the measurement of flows in shallow open channels. This problem is now discussed because of the fact that at low water there are difficulties with the use of most methods of measuring the flow rate [10], [11].

An analysis of the available literature indicates that imaging techniques (photos and video) are gaining in popularity and the quality of the flow analysis, and even in the field of hydraulic modelling [12]. However, some studies show that LSPIV has a low potential to measure the velocity [13].

The analysis of mentioned experiences and obtained effects resulted in creation of the concept of measuring and processing (geometrization) measurements in such a way that significant problems that are emphasized in the literature can be possibly eliminated.

\section{Description of the experiment}

In the course of the experiment realization, the following have been indicated among other possible improvements:

- elimination of the influence of the optical distortion (radial and tangential distortion) and the geometry of the image sensor in digital cameras;

- the possibility of geometrization of the liquid surface in 3D space results;

- photo-synchronous (two or more cameras) registration of moving objects and liquid particles moving with the flow, with simultaneous synchronization in time for two (or more) digital cameras;

- the automation of measuring image pixel coordinates (on stereo pairs) on the basis of images correlation algorithms (increase of data gain for the construction of 3D model);

- the automation of images correlation - finding homologous points;

- the use of floats allows for better images correlation, tracing of the paths followed by the floats in the mainstream and its neighborhood; separate issue is the design of the float (flow indicator) dictated by the shape of the channel cross-section shape.

Most of the mentioned opportunities to improve the quality of the results were introduced in the presented method. Works on automatic correlation are still in the implementation phase. When taking pictures of open channels, the body part of the stereo pair image area is taken by water. Especially in case of calm and slow flowing waters combined with the reflections of the free surface of water there are difficulties with automatic search or indication of the two identical image points on the images. So undoubtedly, the use of floats significantly increases the number of points of correlation for images and allows for more efficient operation of stereo pairs images correlating algorithms.

In the described experiment, the synchronous stereophotographs supported with digital photogrammetry tools has been used making it possible to:

- record dynamic changes and deformations on the surface of the channel or in the cross section separated with the transparent wall of the laboratory channel;

- analyze the steady and laminar and turbulent flows;

- reproduce the shape of the channel surface in 3D space (local or field spatial coordinates).

In order to verify the proposed method, the two cameras of Canon EOS 5D equipped with synchronous shutter and photographic tripods were used. Test measurements took place in the hydro engineering laboratory of Faculty of Civil and Environmental Engineering of Gdansk University of Technology, but due to the need to assess the actual size of the field, the relevant experimental work has been carried on Radunia Channel in the center of Gdańsk. This channel (due to a slight decrease, bottom and side walls are lined with brick and the low level of water) meets the model parameters for the implementation of the test of described method. The channel has a width of 5 meters and is located in a sheltered (from the wind) brick gutter with nearly 3 - meter guards. At about 100 meters this is a channel with features of the prism channel (cross-sectional shape, bottom slope of the channel and its roughness does not change at the length of the channel covered by the experiment).

The role of flow rate indicators is played by colored floats with a spherical element on the water surface.

In the stream and channel there are additional metric elements to evaluate the results of measurements obtained in the photogrammetric images processing.

\section{Numerical analysis}

The study of liquid flow described in the present paper is based on the computer 3D reconstruction using the recorded imaging material (stereo-pair). 


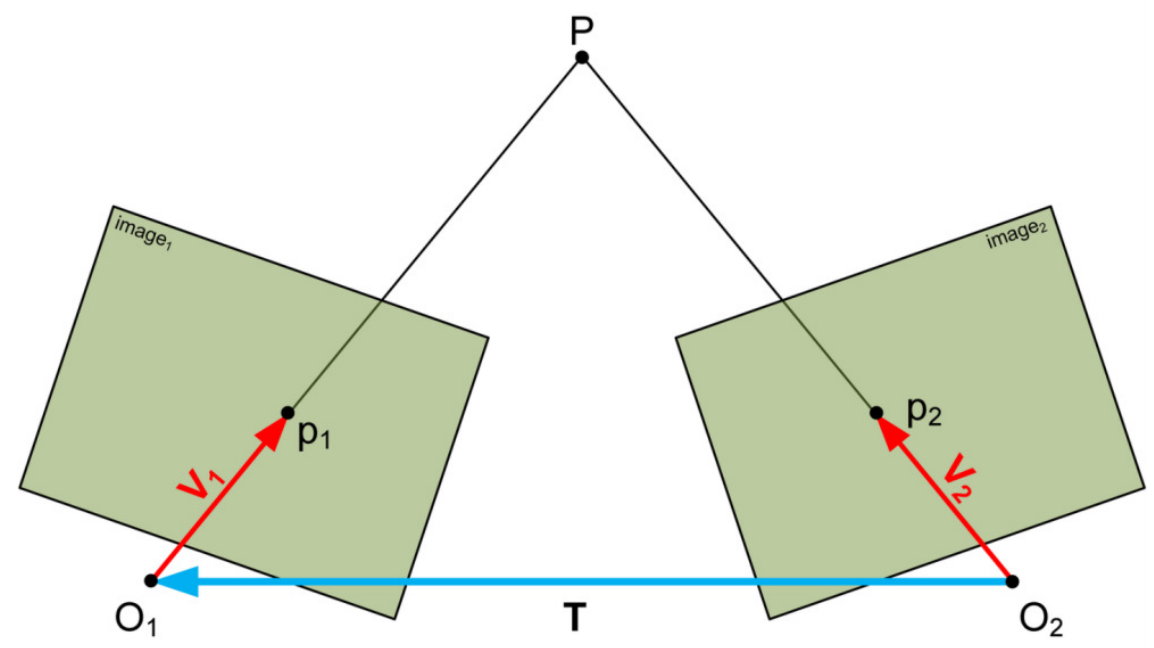

Fig. 1. Geometric realization of stereoscopic model

The literature of the subject matter distinguishes three classic approaches to the reconstruction of the model, depending on the scope of the known parameters related to exposure:

- both intrinsic matrix $\mathbf{K}$ and extrinsic parameters matrix $\mathbf{R} \mid \mathbf{T}$ known;

- only intrinsic known;

- only correspondences.

Having the set of synchronously running and previously calibrated cameras [14], it has been decided to apply variant 2 . In photogrammetric studies, it is significant to determine the radial and tangential factors for each camera. The distortion is characterized by two coefficients of radial distortions $r 1, r 2$ and three coefficients of tangential distortions $q 1, q 2, q 3$ (distortion coefficients $\left[r_{1} r_{2} q_{1} q_{2} q_{3}\right]$, Brown's distortion model [15], [16]). The distortion influences on results of photogrammetric measurement. It was subject of author's interests [17], [18].

The knowledge of the intrinsic matrices being the derivatives of the cameras calibration process allowed (along with synchronous recording the same identifiable actual 3D points on two images) to recover the extrinsic matrix and from this the $3 \mathrm{D}$ model of the recorded object.

The model means (in this case) the restoration of the relationship between the recorded points (angles, distances, the correctness of the left / right positions - spatial orientation), but without the knowledge of the object scale in relation to the real imaged elements and its location in real 3D space. Also the locations of cameras projection centers are unknown.

From the point of view of fluid flow velocity measurements, it is important to achieve a model scale equals 1 in relation to the actual field dimensions and in some cases it is significant to achieve the coplanarity of XY planes of model and the real world and sometimes also XZ and YZ' (model levelling and orientation in relation to the field object).

Most of the solutions based only on the knowledge of intrinsic matrices (literature usually raises the solutions realized with one camera from two locations) suggest to calculate at first the fundamental matrix, and then (on this basis) to calculate $\mathbf{E}$ matrix (matrix described in later part of the study) when $\mathbf{K}$ is known [19-21]:

$$
F=K^{T} E K .
$$

Measuring case described in the publication is the system of two calibrated cameras that synchronously record the observed elements of space, hence the need to calibrate two devices and to obtain intrinsic matrices $\mathbf{K}_{\mathbf{1}}$ and $\mathbf{K}_{\mathbf{2}}$ :

$$
K=\left[\begin{array}{ccc}
\alpha_{x} & \gamma & x_{0} \\
0 & \alpha_{y} & y_{0} \\
0 & 0 & 1
\end{array}\right],
$$

where: $x_{0}, y_{0}-$ coordinates of origin point in pixels;

$\gamma$-represents the skew coefficient between the $\mathrm{x}$ and the $\mathrm{y}$ axis, and is often 0 ;

$\alpha_{x}=f \cdot m_{x}, \alpha_{v}=f \cdot m_{v},-$ represent focal length in terms of pixels,

$m_{x}, m_{v}$ - scale factors relating pixels to distance [22].

In this situation $F=K_{1}^{T} E K_{2}$.

When taking stereoscopic pictures (Fig. 1), the two cameras record on their imaging planes the same field point P. These are respectively for cameral (projection center at O1) and camera2 (projection center at O2) p1 and p2 points. By combining the obtained images of points with centers of camera projections (recorded by these cameras) it is possible to indicate $\mathbf{V}_{1}$ and $\mathbf{V}_{\mathbf{2}}$ vectors. While moving the $\mathrm{O} 2$ center of camera2 in relation to the $\mathrm{O} 1$ center of cameral is a $\mathbf{T}$ vector. 


$$
T=\left[\begin{array}{l}
T_{1} \\
T_{2} \\
T_{3}
\end{array}\right]
$$

The system of these three vectors during the implementation of synchronized exposure for two cameras is located in one plane. Hence the realization of 3D model reproduction from the images captured using stereoscopic camera uses the assumption of vectors coplanarity which is basic in computer vision and this can be saved as the mixed product of vectors:

$$
V_{1} \cdot\left(T \times V_{2}\right)=0
$$

The coordinates of $\mathbf{V}_{\mathbf{1}}$ and $\mathbf{V}_{\mathbf{2}}$ vectors are expressed in systems associated with cameras by which the images were captured and they are expressed as normalized coordinates (for this purpose it is required to use $\mathbf{K}_{\mathbf{1}}$ and $\mathbf{K}_{\mathbf{2}}$ matrix) and they are as follows:

$$
V_{1}=\left[\begin{array}{c}
x_{1} \\
y_{1} \\
1
\end{array}\right] ; \quad V_{2}=\left[\begin{array}{c}
x_{2} \\
y_{2} \\
1
\end{array}\right] .
$$

Realization of condition (4) requires a description of the $\mathbf{V}_{\mathbf{2}}$ vector in cameral coordinate system. So, it is required to carry out the rotation of the coordinate system associated with camera2 to the cameral system. The $\mathbf{R}$ rotation matrix of size $3 \times 3$ is responsible for this. Then the equation ion (4) can be expressed as:

$$
V_{1} \cdot\left(T \times R V_{2}\right)=0
$$

For more convenient record and computation in the form of a matrix, by replacing the vector product with the matrix product which uses skew symmetric matrix $[\mathbf{t}]_{\mathbf{x}}$ the equation (6) can be expressed as:

$$
V_{1} \cdot\left([t]_{x} R V_{2}\right)=0 \text {, }
$$

where:

$$
[t]_{x}=\left[\begin{array}{ccc}
0 & -T_{3} & T_{2} \\
T_{3} & 0 & -T_{1} \\
-T_{2} & T_{1} & 0
\end{array}\right] .
$$

By introducing the matrix:

$$
E=[t]_{x} R=\left[\begin{array}{lll}
E_{11} & E_{12} & E_{13} \\
E_{21} & E_{22} & E_{23} \\
E_{31} & E_{32} & E_{33}
\end{array}\right]
$$

into Eqn. (7) conditions equation (4) will have the following shape in the matrix record:

$$
V_{1}^{T} E V_{2}=0 .
$$

E matrix is called as essential matrix and illustrates the interrelation of homologous points in the shared 3D space, expressed in the cameral system (using pinhole cameras). It has a size of $3 \times 3$ and theoretically it contains 9 unknowns. However, looking at the equation (10) it can be noticed that multiplying its left side in scalar by any number will not change the result of this equation. It results that the $\mathbf{E}$ matrix has an infinite number of possible values that, satisfying the condition (10), differ each other with respect to scaling. Hence the $\mathbf{E}$ matrix contains 8 instead of 9 unknowns describing rotations and translations between systems of camera 1 and 2 not indicating the value of translation linear components scale). The last statement indicates that for the unambiguous determination of $\mathbf{E}$ matrix values we need 8 pairs of homologous coordinates of points that give us 8 equations of type 10). The system of these equations can be saved as a matrix:

$$
A x=0 \text {, }
$$

where:

$$
\begin{gathered}
A=\left[\begin{array}{lllllllll}
x_{1} x_{2} & x_{1} y_{2} & x_{1} & y_{1} x_{2} & y_{1} y_{2} & y_{1} & x_{2} & y_{2} & 1
\end{array}\right], \\
x=\left[\begin{array}{lllllllll}
E_{11} & E_{12} & E_{13} & E_{21} & E_{22} & E_{23} & E_{31} & E_{32} & E_{33}
\end{array}\right]^{T}
\end{gathered}
$$

and calculate using the eight-point algorithm [23].

Due to errors of the registration of homologous points in the image planes, errors of their coordinates readout and the nature of the limited accuracy of the numerical process it is assumed to take a greater number of points used to designate the 
E matrix and from system of equations (11) we do not expect the exact fulfillment of the condition (11) for all equations but the best possible approximation it means the sum of the squares of the left sides of Eqn. (10) is equal to the minimum. For this purpose, a Singular Value Decomposition is used to find A matrices from the equations of (11)

$$
E=U S V^{T} .
$$

Searched parameters of $E_{11}-E_{33}$ are in the last column of the $\mathbf{V}$ matrix, defined in Eqn. (14) because of the nature of the distribution of non-negative singular values on the main diagonal of $\mathbf{D}$ matrix (sorted from the largest to the smallest). This is an approximation of $\mathbf{E}$ matrix, realized with an optimistic assumption that the last element on the diagonal on $\mathbf{D}$ matrix equals zero. In fact, for previously stated reasons, such case does not occur but it is being forced (E must have a rank $=2$ ) by the calculation of the next value of $\mathbf{E}$ matrix as $\mathbf{E}$ ' from the formula:

$$
E^{\prime}=\operatorname{Udiag}\left(s\left(\frac{s_{11}+s_{22}}{2}, \frac{s_{11}+s_{22}}{2}, 0\right) V^{T} \quad \text { or directly } \quad E^{\prime}=\operatorname{Udiag}\left((1,1,0) V^{T},\right.\right.
$$

where $S_{11}$ and $S_{22}$ are the first two elements of the diagonal of $\mathbf{S}$ matrix. By subjecting again the E' matrix to the SVD decomposition:

$$
E^{\prime}=U S V^{T} \quad \text { and assuming matrix } \quad W=\left[\begin{array}{ccc}
0 & -1 & 0 \\
1 & 0 & 0 \\
0 & 0 & 1
\end{array}\right] .
$$

It is possible to separate matrices $[\mathbf{t}]_{\mathbf{X}}$ and $\mathbf{R}$. Each of them adopt one of two values thus giving the four possible solutions of matrices combination $[\mathbf{t}]_{\mathrm{x}}$ and $\mathbf{R}$ :

$$
\begin{gathered}
{[t]_{x 1}=\left[\begin{array}{l}
U_{31} \\
U_{32} \\
U_{33}
\end{array}\right] \text { or }[t]_{x 2}=-\left[\begin{array}{l}
U_{31} \\
U_{32} \\
U_{33}
\end{array}\right]} \\
R_{1}=U W V^{T} \text { or } R_{2}=U W^{T} V^{T}
\end{gathered}
$$

In order to determine which of the pair $[\mathbf{t}]_{\mathbf{x}}$ and $\mathbf{R}$ is valid, it is necessary to select one of pairs used to estimate $\mathbf{E}$ matrix of $\mathrm{p} 1$ and $\mathrm{p} 2$ homologous points (represented by normalized $\mathbf{V}_{1}$ and $\mathbf{V}_{\mathbf{2}}$ vectors), imaging the $\mathrm{P}$ field point. It may be assumed that $\mathrm{p} 1$ and $\mathrm{p} 2$ imaging were generated as a result of projections determined by $\mathbf{M}_{1}$ and $\mathbf{M}_{2}$ matrices (size of $3 \times 4$ ) of $\mathrm{P}$ on the imaging planes of camera 1 and 2.

$$
\begin{aligned}
& p_{1}=M_{1} P \\
& p_{2}=M_{2} P
\end{aligned}
$$

Since the pair of corresponding $[\mathbf{t}]_{\mathbf{x}}$ and $\mathbf{R}$ indicates the relationship of the coordinate system of a second camera to the coordinate system of the first one, it is possible for the assessment of each $[\mathbf{t}]_{\mathrm{x}}$ pair and $\mathbf{R}$ assume that:

$$
M_{1}=\left[\begin{array}{llll}
1 & 0 & 0 & 0 \\
0 & 1 & 0 & 0 \\
0 & 0 & 1 & 0
\end{array}\right]
$$

Where as

$$
M_{2}=H^{-1}
$$

where:

$$
H=\left[\begin{array}{cc}
R_{i} & {[t]_{x j}} \\
0 & 1
\end{array}\right] \text { for } i=1 . .2, j=1 . .2
$$

then the following system of equations is true:

$$
\left\{\begin{array}{l}
{\left[p_{1}\right]_{x} M_{1} P=0} \\
{\left[p_{2}\right]_{x} M_{2} P=0}
\end{array}\right.
$$

which can be symbolically expressed as:

$$
B P=0
$$


$\mathbf{P}$ vector may be calculated by subjecting $\mathbf{B}$ matrix to SVD decomposition:

$$
B=U S V^{T} .
$$

$\mathbf{P}$ vector will be equal to the last column of the $\mathbf{V}$ matrix. After its normalization, it is necessary to calculate the position of P point with respect to the camera 2, i.e. P':

$$
P^{\prime}=M_{2} P .
$$

If the components of the vectors $\mathrm{P}$ and $\mathrm{P}^{\prime}$ are respectively upstream cameral and cameral, this pair of $[\mathbf{t}]_{\mathbf{x}}$ and $\mathbf{R}$ (the only one among the four) is correct and they are used in formulas (24) to calculate the coordinates in the model system of all points measured in the image. The model system is a system in which there is an isometry of points position in relation to their equivalents from the real world but the scale is not determined. The literature of the subject matter points out in this case to indicate two points of the model for which the distance is known in the field and to carry out the scaling of the entire system. Author's application allows you to specify at least one pair of such points, and on this basis to determine the average scale of the estimated model.

The knowledge of field coordinates of three points imaged on the stereo pair will give the possibility to level the model. This solution may be required in hydrological analyzes taking into account declines in the water level.

\section{Example of method use}
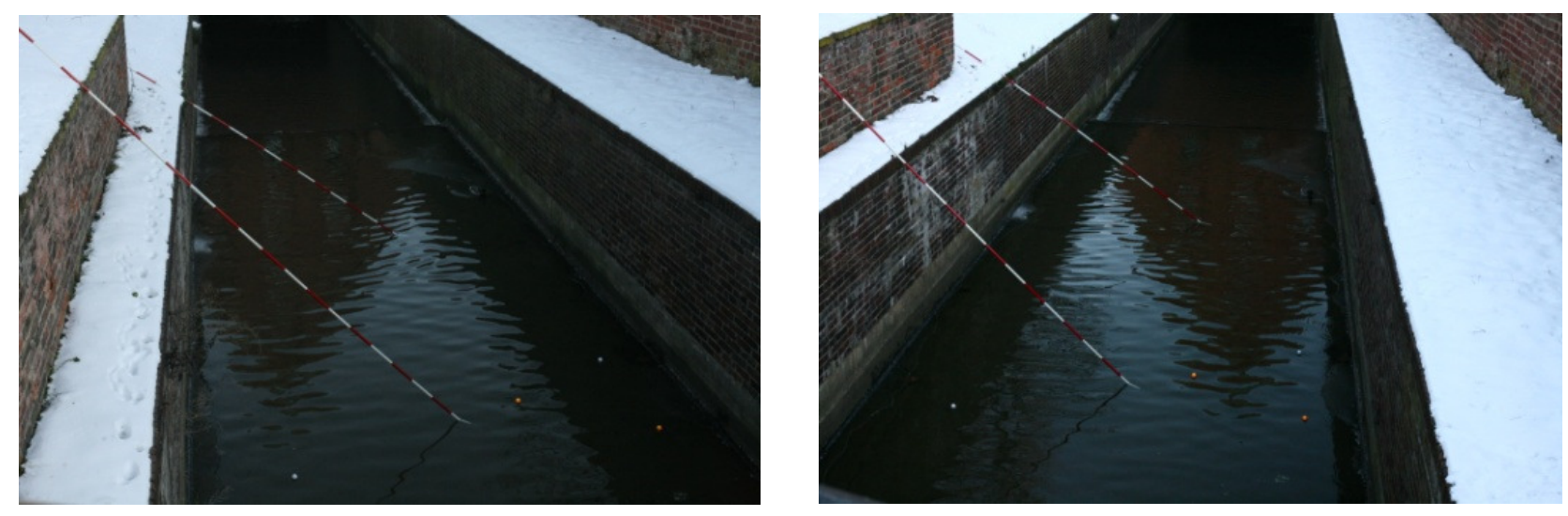

Fig. 2. Visualization of stereo pair (left and right image)

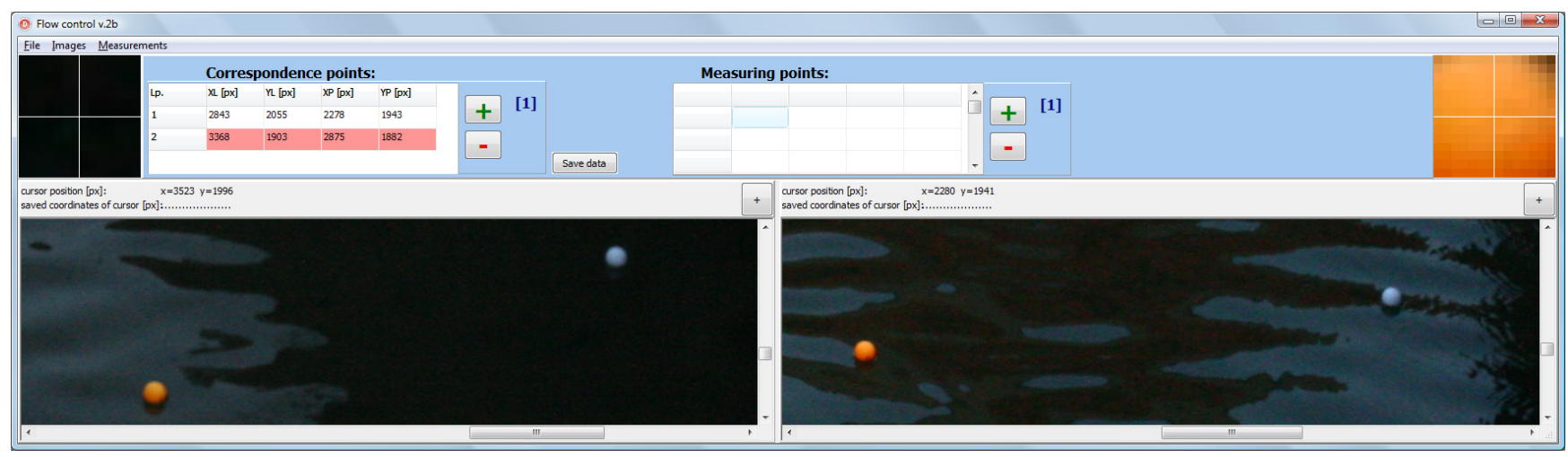

Fig. 3. The main window of the author's application with loaded data for one stereo pair

During the examination of the flow rate of water in the Radunia Channel, the series of synchronous stereo pairs with 1 second time interval were made. Due to the slow movement of the water, the numerical analysis used selected stereo pairs with time parallax of $15 \mathrm{~s}$.

The resolution of cameras amounting to $12.71 \mathrm{Mpx}(4368 \times 2912$ pixels), used aperture of the lens $\mathrm{f} / 11$, exposure time $1: 400 \mathrm{~s}$, ISO 1600 , focal length $\sim 50 \mathrm{~mm}$, are suitable for observations on the $24^{\text {th }}$ of January 2014 . The restoration error of the 3D model of the test length linear elements contained in the objective space does not exceed $0.0046 \mathrm{~m}$.

The aim of the experiment was to examine an opportunity to use the stereo photogrammetric elaborations and time parallax to the hydrological applications. Therefore, the trajectory of only five flow rate indicators was subjected to the measurements. For each measurement epoch, the 3D model was created, which has been scaled with isometric projection to the actual field size. From the comparison of 3D models and indicators projection on XY plane the next points of particular indicators were obtained (Fig. 4). 


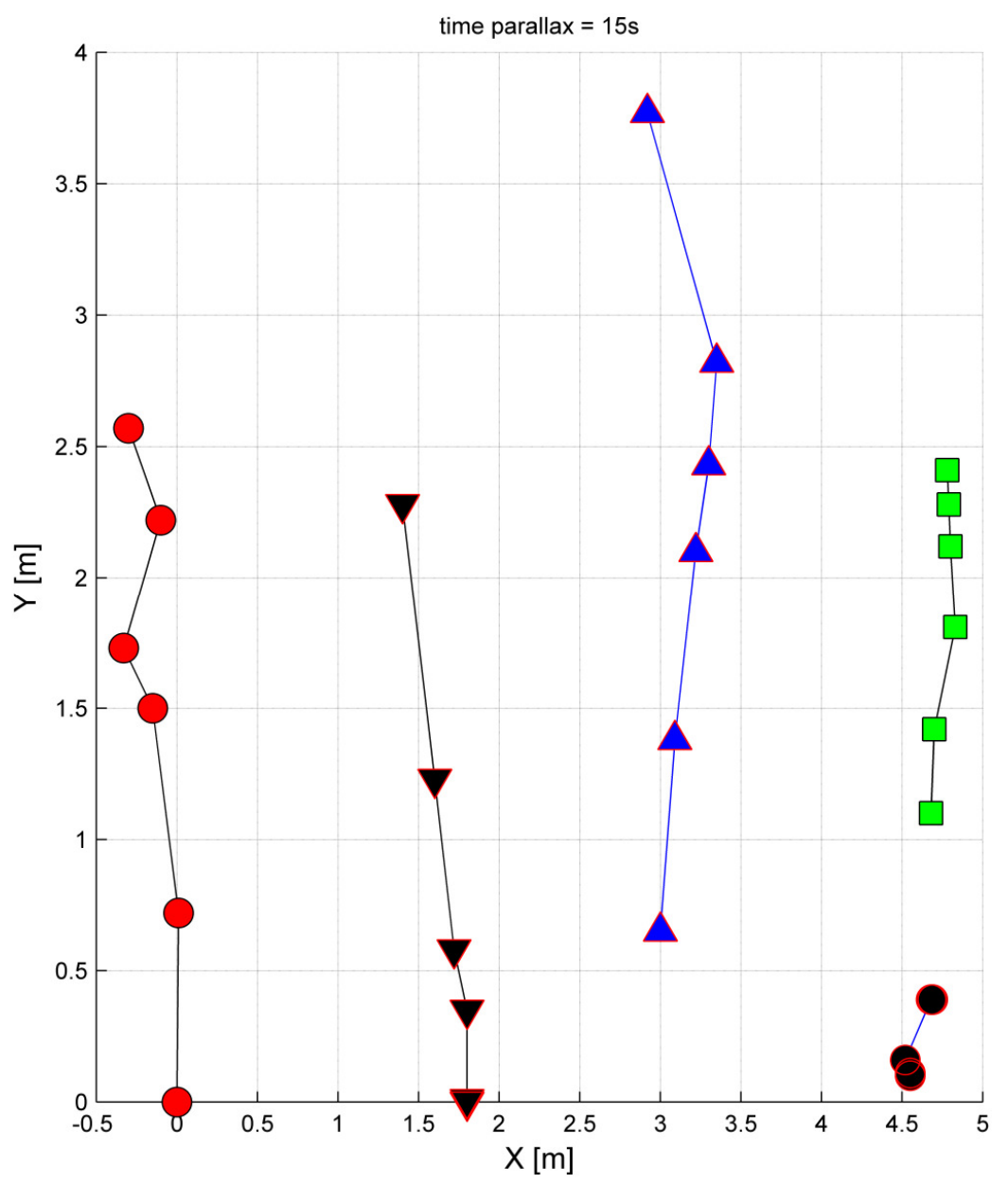

Fig. 4. Chart of the indicator positions in time (projection on XY plane)

\section{Conclusions}

Numerical results, obtained during the realization of the experiment can be connected with the data originating from other measurement methods used in hydrology. The presented measurements are verifiable and can be calibrated on the basis of the field and laboratory tests, performed using the measurement methods approximating more accurately the actual movement of the fluid.

The use of mathematical apparatus in the field of close range photogrammetry ensures a very high accuracy of the measurement method (subpixel results level) but the result which characterizes the flow rate depends also on the choice of indicators of flow or support with other measurement methods.

The presented method makes it possible to compare flow rate values results (in the representative observation cycles for individual watercourse) on the basis of images captured at different time (in measurement epochs) using the so-called time parallax. The method allows for the measurement of the coordinates (and on this basis it is possible to carry out the measurement of straight elements lengths, slope values, surface areas) on the surface of liquids in open channels (natural and artificial) and in laboratory test channels (on the surface of liquid or with the use of transparent sidewalls - when taking into account the Snell's law).

\section{References}

[1] Jeżowiecka-Kabsch, K.; Szewczyk, H. 2001. Mechanika płynów. Wrocław: Oficyna Wydawnicza Politechniki Wrocławskiej.

[2] Michalski, A. 2004. Pomiary przeplywu wody w kanałach otwartych. Warszawa: Politechnika Warszawska. ISBN 83-7207-466-6.

[3] Pomianowski, K. M.; Rybczyński, M.; Wóycicki, K. 1939. Hydrologia. vol. 3, Hydrografia i hydrometria wód powierzchniowych. Warszawa: Politechnika Warszawska.

[4] Dynowska, I.; Tlałka, A. 1982. Hydrografia. Warszawa-Poznań: PWN.

[5] Piechurski, F. 2012. Przeglądowa ocena urządzeń do pomiaru przepływu ścieków, Napędy i Sterowanie 14(2): 64-71.

[6] Artichowicz, W. 2011. Numerical analysis of open channel steady gradually varied flow using the simplified Saint-Venant equations, TASK Quarterly 15(3-4): 317-328.

[7] Szydłowski, M.; Szpakowski, W.; Zima, P. 2013. Numerical simulation of catastrophic flood: the case study of hypothetical failure of the Bielkowo hydro-power plant reservoir, Acta Geophysica 61(5): 1229-1245. http://dx.doi.org/10.2478/s11600-013-0104-6 
[8] Weitbrecht, V.; Kühn, G.; Jirka, G. H. 2002. Large scale PIV-measurements at the surface of shallow water flows, Flow Measurement and Instrumentation 13(5-6): 237-245. http://dx.doi.org/10.1016/S0955-5986(02)00059-6

[9] Albayrak, I.; Lemmin., U. 2007. Large Scale PIV - measurements on the water surface of turbulent open-channel flow, in 18ème Congrès Français de Mécanique Grenoble, 27-31 août 2007.

[10] Kantoush, S. A.; Schleiss, A. J. 2009. Large-scale PIV surface flow measurements in shallow basins with different geometries, Journal of Visualization 12(4): 361. http://dx.doi.org/10.1007/BF03181879

[11] Fujita, I.; Komura, S. 1994. Application of video image analysis for measurements of river-surface flows, in Proc. Hydraul. Eng., JSCE 38: 733-738.

[12] Xiong, M. Z.; Schöne, J.; Li, Z. 2004. Validation and Extension of Image Velocimetry Capabilities for Flow Diagnostics in Hydraulic Modeling, Jurnal of Hydraulic Eng. 130(3): 175-185. http://dx.doi.org/10.1061/(ASCE)0733-9429(2004)130:3(175)

[13] Kantoush, S. A.; De Cesare, G.; Boillat, J. L.; Schleiss, A. J. 2008. Flow field investigation in a rectangular shallow reservoir using UVP, LSPIV and numerical modelling, Flow Measurement and Instrumentation 19(3-4): 139-144. ISUD 5, in The $5^{\text {th }}$ International Symposium on Ultrasonic Doppler Methods for Fluid Mechanics and Fluid Engineering.

[14] Sawicki, P. 2003. Kalibracja równoczesna aparatu cyfrowego Kodak DC4800 w procesie fotogrametrycznego pomiaru punktów w bliskim zasięgu. Archiwum Fotogrametrii, Kartografii i Teledetekcji 13b: 457-466.

[15] Duane, C. B. 1971. Close-range camera calibration, Photogrammetric engineering 37(8): 855-866.

[16] Fryer, J. G.; Brown, D. C. 1986. Lens distortion for close-range photogrammetry, Photogrammetric engineering and remote sensing 52(1): 51-58.

[17] Janowski, A.; Sawicki, P.; Szulwic, J. 2005. Advanced 3D Visualization of an Architectural Object in the OpenGL Standard, The International Archives Of Photogrammetry, Remote Sensing and Spatial Information Sciences, 36, 2.

[18] Janowski, A.; Sawicki, P.; Szulwic, J. 2005. Metoda wizualizacji 3D w standardzie OpenGL obiektów bliskiego zasięgu, Archiwum Fotogrametrii, Kartografii i Teledetekcji vol. 16. ISBN 978-83-920594-5-X.

[19] Hartley, R. I. 1992. Estimation of relative camera positions for uncalibrated cameras, in Proceedings of the Second European Conference on Computer Vision, 579-587.

[20] Luong, Q. T. 1992. Fundamental matrix and self-calibration, PhD Thesis, University of Paris, Orsay.

[21] Whitehead, A.; Roth, G. 2004. Estimating intrinsic camera parameters from the fundamental matrix using an evolutionary approach, EURASIP Journal on Advances in Signal Processing 2004(8): 1113-1124. http://dx. doi.org/10.1155/S1110865704401024

[22] Hartley, R.; Zisserman A. 2003. Multiple View Geometry in Computer Vision. Cambridge University Press, 155-157. ISBN 0-521-54051-8.

[23] Hartley, R. I. 1997. In defense of the eight-point algorithm, Pattern Analysis and Machine Intelligence, IEEE Transactions on 19(6): 580-593. 